\title{
Characterization of Tool Wear in High-Speed Milling of Hardened Powder Metallurgical Steels
}

\author{
Fritz Klocke, Kristian Arntz, Gustavo Francisco Cabral, Martin Stolorz, and Marc Busch
}

Fraunhofer Institute for Production Technology IPT, Steinbachstraße 17, 52074 Aachen, Germany

Correspondence should be addressed to Marc Busch, marc.busch@ipt.fraunhofer.de

Received 30 June 2011; Accepted 29 August 2011

Academic Editor: Alexander Tsouknidas

Copyright ( 2011 Fritz Klocke et al. This is an open access article distributed under the Creative Commons Attribution License, which permits unrestricted use, distribution, and reproduction in any medium, provided the original work is properly cited.

In this experimental study, the cutting performance of ball-end mills in high-speed dry-hard milling of powder metallurgical steels was investigated. The cutting performance of the milling tools was mainly evaluated in terms of cutting length, tool wear, and cutting forces. Two different types of hardened steels were machined, the cold working steel HS 4-2-4 PM (K490 Microclean/66 HRC) and the high speed steel HS 6-5-3 PM (S790 Microclean/64 HRC). The milling tests were performed at effective cutting speeds of 225,300 , and $400 \mathrm{~m} / \mathrm{min}$ with a four fluted solid carbide ball-end mill ( $D_{0}=6$, TiAlN coating). It was observed that by means of analytically optimised chipping parameters and increased cutting speed, the tool life can be drastically enhanced. Further, in machining the harder material HS 4-2-4 PM, the tool life is up to three times in regard to the less harder material HS 6-5-3 PM. Thus, it can be assumed that not only the hardness of the material to be machined plays a vital role for the high-speed dry-hard cutting performance, but also the microstructure and thermal characteristics of the investigated powder metallurgical steels in their hardened state.

\section{Introduction and Motivation}

1.1. Applications. In the economically efficient large batch production of complex functional and structural components, the moulding and forming technologies are of crucial importance. The performance of these technologies is significantly defined by the material, the surface conditions, and the subsurface integrity of the manufactured tools, dies, and moulds. Conventional tool steels are increasingly reaching their limits and, therefore, restrain a further development in the large-scale production techniques, considering higher economic efficiency and process stability. Alternatively, highperformance materials like powder metallurgically produced steels [1] can be applied. Compared to conventionally produced tool steels, they verifiably reach a multiplicatively enhanced life of the manufactured tools, dies, and moulds. However, the machining of these superhard steels by multiaxis milling represents a major challenge and is, therefore, an issue of highest interest, both for the scientific research and the industrial production [2-5]. Due to their sophisticated material properties, such as their high hardness, ductility, and pressure strength [4], they can be loaded up to high mechanical stresses. This represents a central requirement for high-value parts and components, as they occur in different areas of application in the tool and die making; see Figure 1.

Due to its efficiency, flexibility, and precision, the complete machining by means of hard milling is one of the key technologies in the tool, die, and mould-making industry. For instance, 5-axis milling enables the manufacture of highvalue parts of highest complexity in one clamping, providing parts and components of excellent surface quality and hence increasing the potential of substituting grinding processes which are often downstreamed to milling. The downside to the geometric flexibility of multiaxis hard milling are the continuously changing chipping conditions, resulting in favourable and unfavourable engagement conditions between the workpiece and the milling tool. In general, second lead to increased loads on the milling tool and hence to reduced tool life time accompanied by a surface damage as well as by a formation of microcracks and structural changes to the subsurface area of the manufactured parts.

However, even along with the highest material requirements and most complex geometries, the simultaneous 5axis hard milling enables optimal process conditions in 


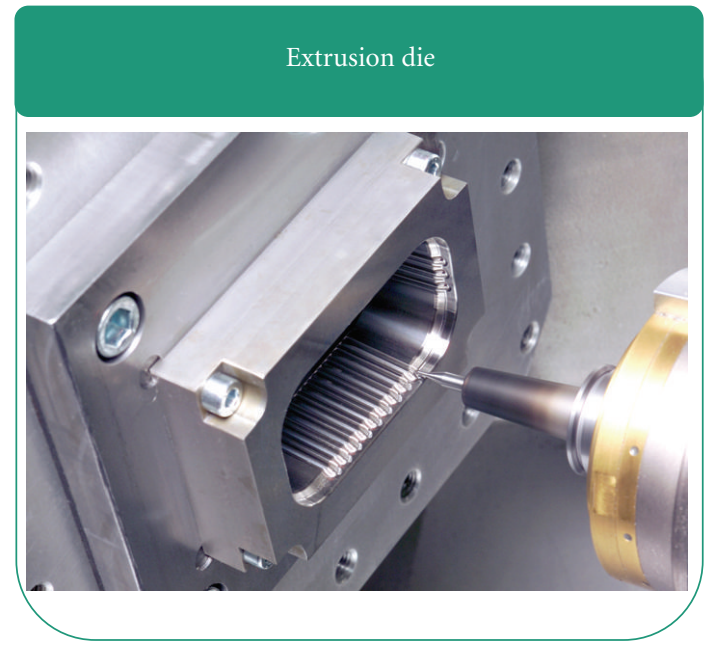

(a)

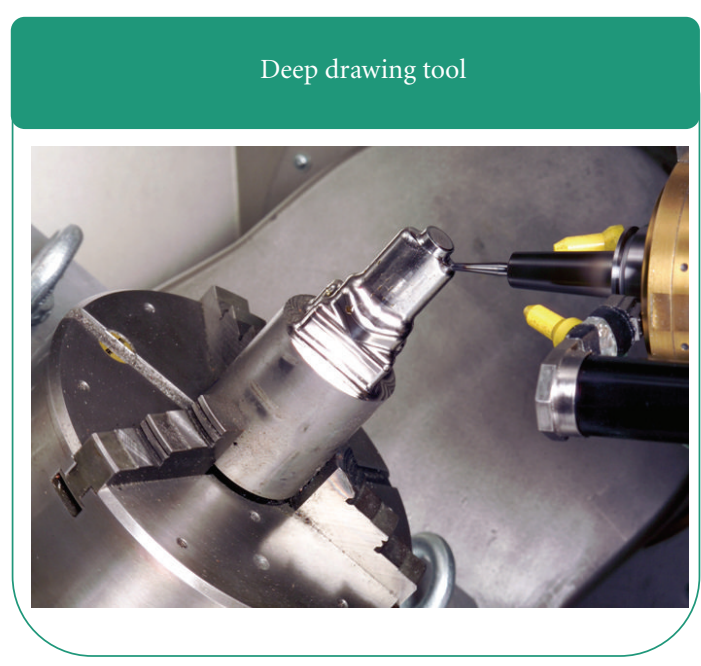

(b)

FIGURE 1: Tool and die making as a representative area of application for 5-axis-milling of superhard steels; (a) Heading tool; (b) Deep drawing tool.

a narrow process tolerance field by a suitable parameter selection and innovative machining strategies. Currently, the state of knowledge on the suitable selection of optimal component- and production-orientated process parameters for the simultaneous 5-axis hard milling of the addressed materials is limited. Therefore, a reliable and efficient production of highly stressed tools, dies, and moulds is not granted, and the potential of high-performance materials is rarely exploited [6].

1.2. Metallurgical Fundamentals. Powder metallurgical (PM) compounded steels, mainly applied in the tool and die making, allow the generation of a homogeneous and isotropic material microstructure. They are characterized by a high hardness, ductility, and pressure strength and possess a good dimensional stability during their heat treatment. Depending on the specific alloy composition and the heat treatment, the hardness can be varied between 50 and 70 HRC. The high hardness of these materials can be reached by carbide precipitation and martensitic transformation [4]. Precipitation hardening, for instance, leads to an improvement of the stability of the workpieces under static and especially pulsatory loads. This leads to a considerably enhanced property profile compared to conventional die materials. Hence, the lifetime of forming tools can be improved drastically.

Furthermore, powder metallurgical steels can be customized referring to the specific area of application with regard to their hardness, heat, and wear resistance or ductility. For instance, the method of spray-compacting permits the adjustment of an extreme wear resistant microstructure due to the high amount of embedded carbides [7-9].

1.3. High-Speed Milling of Superhard Materials. A recently conducted survey of the Fraunhofer IPT exhibits that highspeed milling of superhard steels will probably develop from a core-technology to the most important technology in the area of tool and die making. The reason for this is the combination of highest productivity and flexibility compared to other competing production techniques. However, regarding to small diameters of milling tools as well as superhard materials, there still exists a great demand for further process optimization in order to realize long tool endurances, short lead times and short time-to-markets.

Inter alia, in milling of superhard steels, the occurring forces in the chipping zone are substantially influenced by three circumstances:

(i) the hardness and microstructure of the material to be machined $[4,10]$,

(ii) the geometry of the uncut chip [11],

(iii) the process parameter $[12,13]$.

The microstructure leads to the fact that during milling, the rake and the clearance face of the tools are loaded with high abrasive wear due to the fine-particle distributed carbides. Furthermore, hard milling of PM steels tends to the formation of build up edges (BUE). BUE develop if parts of the machined material are cemented at the tools' cutting edge. Here, they form a superhard layer due to the material characteristics and take over the function of the cutting edge. According to the cutting conditions, small particles of the BUE are separated and slide away between the clearance and cutting area. As a consequence, the flank wear increases dramatically, and the surface properties of the machined parts are deteriorated significantly [14].

Furthermore, Kochy et al. and Okada et al. assume that along with an increasing material hardness, the wear of the milling tool increases significantly and that the microstructure of the component material also has a great impact on the progressive wear behaviour of the milling tool $[15,16]$. 
The geometry of the uncut chip is mainly represented by the local thickness of the chip to be removed $h_{\mathrm{sp}}$ and the related cross-section of the chip $A_{\mathrm{sp}}$. The cross-section represents the amount of material in front of the cutting edge.

Hence, a vital issue for process design is to adapt the uncut chip geometry according to the material properties and the specific machining task. For exemplification, according to the microstructure of the material to be machined, different process parameters resulting in different uncut chip geometries offer optimized process performance. In case of the dimension and distribution of the embedded carbides, higher cutting depths may result in lower tool wear due to the fact that the carbides are unhinged out of the metal matrix in one part and do not have to be cut within several tool engagements.

Salomon already postulated a first hypothesis, stating that an increasing cutting speed reduces the cutting forces and the wear of the milling tool as well as explicitly enhances the flow behaviour and deformation rate of the material to be processed [13]. In order to prove these chipping mechanisms, the complex interactions between the deformation rate, the elevated process temperature, the strength properties and the microscopic flow behaviour and the structural integrity of the material in the local contact zone between the work piece and the milling tool have to be taken into consideration $[17,18]$. In a milling process of different machine materials, the progressive wear of the milling tool $[16,19,20]$, the elevated process temperature $[20,21]$ and the roughness of the generated surface increase proportionally with an increasing cutting speed [19]. According to [12], the wear of the milling tool spreads with the highest effective cutting speed, starting at the engagement point of the cutting edge, and can be reduced by an adequate increase of the feed per tooth. If the feed per tooth and the cutting speed in the hard milling process fall below a critical value, the tool vibrations increase, and the tool wear grows significantly [12].

Because of the clearly increased mechanical and especially thermal load in the contact area between the work piece and the milling tool, the continuum mechanical processes on the components surface and subsurface area, that are induced by the HSC-hard milling process, need to be systematically examined and made uniquely describable. This includes in particular the associated softening of the structure [22] and the rehardening [23] as well as the controlled introduction of compressive and tensile residual stress and the avoidance of thermal damages in the form of so-called "white layers" [23].

1.4. Objectives and Challenges for Process Layout. As shown above, presently, the procedures and interdependencies of work piece material and process parameter during the chip formation process of powder metallurgical compounded tool materials is only known partially. In this connection, a major issue beside the material analysis is the detailed investigation of the influence of the resulting chip geometry regarding different process parameters, as they are of vital importance for the process performance of high-performing

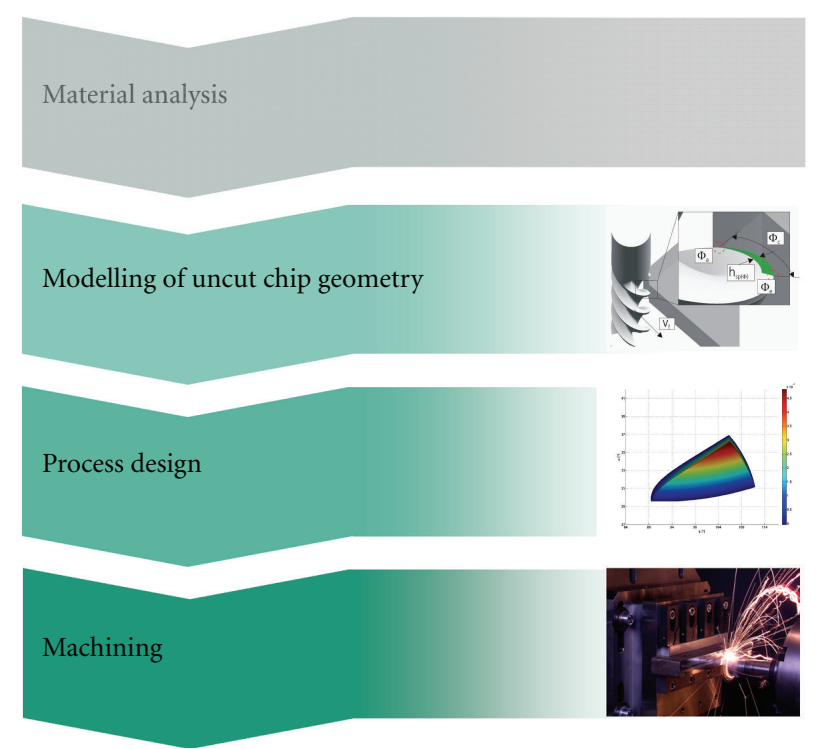

Figure 2: Approach for optimizing milling process design on base of modelling the uncut chip geometry.

milling processes like 5-axis-high-speed cutting. On this base, milling process design can be optimized without timeand cost-consuming trial-and-error tests before machining; see Figure 2.

Referring to this, the paper in hand focuses on the issues modelling, process design, and machining. An approach will be presented, enabling an optimization of process design on basis of a theoretical analysis of the uncut chip geometry. In machining tests, the wear mechanisms in milling superhard powder metallurgical alloys will be investigated and linked to the uncut chip geometry.

\section{Experimental Method}

2.1. Experimental Conditions and Work Piece Materials. In this experimental study, the applied milling tool was a commercial solid carbide ball-end mill (Table 1). The tool had a nominal diameter of $6 \mathrm{~mm}$ and four flutes. Two flutes coincided in the centre tool tip point (axial immersion angle $\kappa=0^{\circ}$ ), and the other two flutes had notches between $\kappa=$ $0^{\circ}-30^{\circ}$. The helix angle was $30^{\circ}$ and the angle of rake $\gamma$ was $-10^{\circ}$. The concentricity tolerance of the tool was less than $\pm 7 \mu \mathrm{m}$. The tool was coated with TiAlN. The milling tests were carried out at a variation of the effective cutting speed $v_{c, \text { eff }}=225,300$, and $400 \mathrm{~m} / \mathrm{min}$. The tool was constantly tilted by a fixed tilt angle $\beta_{\mathrm{fn}}=75^{\circ}$, value chosen after performing an analytical simulation of the chip geometry. This tool orientation provides a high effective cutting speed in the surface generating area and a moderate distribution of the chip cross-sectional surface along the cutting edge. At the same time, it avoids cutting with the centre tool tip and provides a moderate chip length distribution, resulting in less tool wear. The feed per tooth was set to $f_{z}=0.05 \mathrm{~mm}$, the radial depth of cut $a_{\mathrm{en}}$ was set to $0.05 \mathrm{~mm}$, and the axial depth $a_{\mathrm{pn}}$ of cut was set to $0.04 \mathrm{~mm}$. For investigating the influence of the feed per tooth $f_{z}$ in terms of tool 
TABLE 1: Experimental conditions.

\begin{tabular}{lc}
\hline Cutting tool & \\
Design of cutting tool & Solid carbide ball-end mill \\
Tool diameter $d(\mathrm{~mm})$ & $6 \mathrm{~mm}$ \\
Flute $(\mathrm{s})$ & 4 \\
Helix angle $\lambda\left(^{\circ}\right)$ & 30 \\
Angle of rake $\gamma\left(^{\circ}\right)$ & -10 \\
Coating & TiAlN \\
\hline Cutting parameters & \\
Effective cutting speed $v_{c, \text { eff }}(\mathrm{m} / \mathrm{min})$ & 225,300 and 400 \\
Effective tool diameter $d_{\text {eff }}(\mathrm{mm})$ & 5.796 \\
Feed per tooth $f_{z}(\mathrm{~mm} / \mathrm{touth})$ & 0.05 \\
Radial depth of cut $R_{d}(\mathrm{~mm})$ & 0.05 \\
Axial depth of cut $A_{d}(\mathrm{~mm})$ & 0.04 \\
Tilt angle $\beta_{\text {fn }}\left({ }^{\circ}\right)$ & 75 \\
Overhang of the tool $(\mathrm{mm})$ & 25 \\
Cutting style & down-cutting \\
Lubricant & dry \\
\hline Machine tool & Mikromat $8 \mathrm{~V} \mathrm{HSC}$ \\
Maximum spindle speed $N\left(\mathrm{~min}{ }^{-1}\right)$ & 24000 \\
Spindle power $P(\mathrm{~kW})$ & 27 \\
Speed of axis $v_{f} x, y, z$ & $(\mathrm{~m} / \mathrm{min})$ \\
Acceleration of axis $a_{x, y, z}(\mathrm{~m} / \mathrm{s} 2)$ & 24 \\
Positioning accuracy $P_{a} / 2(\mathrm{~mm})$ & 4 \\
Control system & 0.001 \\
Drive & Andronic 400 \\
\hline
\end{tabular}

life and progressive tool wear on a random basis, $f_{z}$ was varied additionally in $0.025 \mathrm{~mm} /$ tooth and $0.075 \mathrm{~mm} /$ tooth for milling tests at $v_{c, \text { eff }}=300 \mathrm{~m} / \mathrm{min}$ and for both addressed work piece materials. The overhang of the tool was $25 \mathrm{~mm}$, while shrinking fit chucks were applied. All milling tests were performed in downmilling without any lubricants at dry conditions using a Mikromat $8 \mathrm{~V}$ HSC hard milling machine tool. To achieve a representative value for the measurand at each operating point, the root sum square was calculated.

Two kinds of powder metallurgical produced steels were used as typical work piece materials for the tool and die making from Böhler, a high-speed steel HS 6-5-3 PM, which was hardened up to $64 \mathrm{HRC}$, and a cold working steel HS 42-4 PM with a hardness of 66 HRC.

\subsection{Measurement of Machining Forces and Tool Life Time.} The tool wear was measured as the width of the tool flank wear land VB $(\mu \mathrm{m})$ with a toolmaker's microscope from Heidenhain (type LS 3003). In case of the high-speed steel HS 6-5-3 PM, respectively, the cold working steel HS 4-2$4 \mathrm{PM}$, the width of tool wear land was measured iteratively after completing $15 \mathrm{~m} / 20 \mathrm{~m}$ in length of cut. The maximum tool life in terms of total length of cut $L_{c, \max }$ was measured after an abort criterion of $75 \mu \mathrm{m}$ of tool flank wear land. The morphology of the functional surface on each tooth of the worn milling tools was characterized using a scanning electron microscope (SEM) (Table 2).
The cutting forces were recorded by a Kistler dynamometer (type $9255 \mathrm{~A}$ ). For characterising the roughness of the generated surface on a random basis, $R_{a}$ was measured after performing of milling tests with a fresh tool at $v_{c, \text { eff }}=$ $400 \mathrm{~m} / \mathrm{min}$ and $f_{z}=0.05 \mathrm{~m}$ on both work piece materials with a Tailor-Hobson surface detector.

\section{Theoretical Analysis of the Chip Geometry}

3.1. Fundamentals of Modelling 5-Axis Ball-End Milling Operations. Knowing the engagement conditions and the chip geometry is the basis for understanding the milling process. It allows the prediction of the process forces and temperature, tool wear, surface quality, form error, and other phenomena related to the milling process.

The main challenge in modelling ball-end milling operations is building a model that is sufficiently accurate and flexible enough to allow the simulation of different tool geometries and engagement conditions, especially in the machining of parts with sculptured surfaces, whereby the contact conditions and the tool orientation often vary widely.

Previous researches [24-31] indicate analytical models as an adequate compromise solution. In this paper, it was thus used an analytical model for describing the chip geometry and the tool engagement condition.

The main purpose of the presented method is to describe the actual chip geometry and to derive characteristic values for identifying favourable cutting conditions. Therefore, the presented model serves as a support tool for selecting optimized cutting parameters.

3.1.1. Ball-End Mill Geometry. The geometry of a ball-end mill is shown in Figure 3. The current cutter angle $\tau_{i}, \kappa_{l}$ off the cutter $i$ in the axial immersion $\kappa$ and in the rotation angle $\Phi$ is given by

$$
\begin{array}{r}
\tau_{i, \kappa_{l}}=\Phi+\Delta \tau \cdot(i-1)-\int_{0}^{\mathcal{K}_{l}} \frac{R_{0} \cdot \tan \left(\lambda_{l}\right)}{2 \pi \cdot R_{0} \cdot \sin (\kappa)} d \kappa, \\
\text { with }: i \in[0, n],
\end{array}
$$

where $\Delta \tau$ is the angle between two consecutive cutting edges

$$
\Delta \tau=\frac{2 \pi}{n} .
$$

The local helix angle $\lambda_{l}$ can be calculated according to Lazoglu and Liang [28] and Zhu et al. [29], who modelled a variable helix angle along the cutting flute. Figure 4 shows the variation of $\lambda_{l}$ with the axial immersion angle $\kappa$ for the milling tool used in the experiments, which has a helix angle of $30^{\circ}$ in the shaft part of the tool.

The contact area for finishing processes is very small, resulting in a small variation of the local helix angle. For the simulated contact conditions, the helix angle varies from $18.5^{\circ}$ to $23.5^{\circ}$. For practical purposes, it was considered constant $\lambda_{l}=21^{\circ}$.

3.1.2. Contact Conditions. Figure 6 shows the contact conditions for ball-end milling. The reference system FCN is 
TABLE 2: Work piece materials.

\begin{tabular}{|c|c|c|}
\hline Powder metallurgical steels & & \\
\hline Term & Cold work steel HS 4-2-4 PM & High-speed steel 6-5-3 PM \\
\hline Hardness (HRC) & 66 & 64 \\
\hline Binder & C Cr Mo V W & C Si Mn Cr Mo V W \\
\hline Modulus of elasticity $E(\mathrm{GPa})$ & 223 & 230 \\
\hline Density $\rho\left(\mathrm{kg} / \mathrm{dm}^{3}\right)$ & 7.79 & 8.0 \\
\hline Thermal conductivity $k(\mathrm{~W} / \mathrm{mk})$ & 19.6 & 24.0 \\
\hline Thermal expansion coefficient $\alpha\left(10^{-6} / \mathrm{K}\right)\left(\right.$ at $\left.100 / 200 / 300 / 600^{\circ} \mathrm{C}\right)$ & 10.6/11.1/11.6/12.6 & $11.5 / 11.7 / 12.2 / 13.0$ \\
\hline Specific heat capacity $c(\mathrm{~W} / \mathrm{mK})$ & 450 & 420 \\
\hline
\end{tabular}

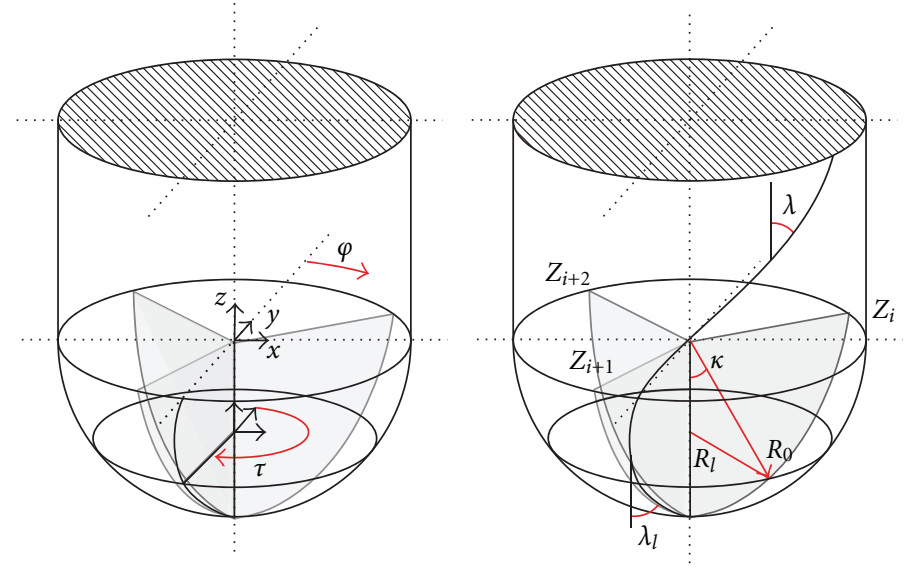

FIgURE 3: Geometry of a ball-end mill.

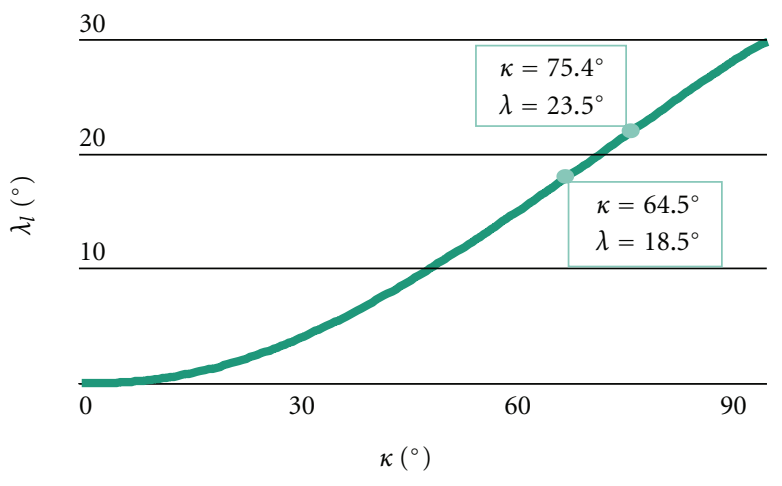

Figure 4: Variation of the local helix angle $\lambda_{l}$ with the axial immersion angle $\kappa$.

defined according to Ozturk and Budak [30]. $F$ is the feed axis, $N$ the surface normal axis, and $C$ the cross-feed axis. $a_{\mathrm{en}}$ is the row width, and $a_{\mathrm{pn}}$ is the cutting depth. C+ indicates that the next row is towards the positive side of the $C$-axis, and $\mathrm{C}-$ is the opposite case; that is, the next row is in the negative direction of the $C$-axis. $f_{z}$ is the feed per tooth.

3.1.3. Simulation Approach. The simulation workflow is shown in Figure 5. First, it is necessary to specify the simulation input, which are the process parameters $a_{\mathrm{pn}}, a_{\mathrm{en}}, f_{z}$, $\mathrm{C}+/ \mathrm{C}-$, the tool orientation and the cutting speed $v_{c}$. It was used a discrete model for the simulation, so the discretization parameters, that is, the $\Phi$ and $\kappa$ angle increments, are also inputs for the simulation.

A similar approach was also used by Urban [31] and Ozturk and Budak [30]. Urban implemented a model which takes into consideration the scallops in the feed direction but does not consider the helix angle. Ozturk calculated the boundary curves without considering the scallops and considered just the area 3 in the modelling (see Figure 8), which can result in an error of up to $40 \%$ in the resulting contact angle for finishing processes, since the areas 2 and 3 are relative larger for small values of $a_{\mathrm{pn}}$ and $a_{\mathrm{en}}$.

Secondly, the boundary curves are calculated, defining the position of the uncut chip in the FCN coordinate system. On the basis of the chip spatial position information and on the input parameters, the detailed uncut chip geometry is determined. The geometry is used for deriving other parameters, for example, chip volume, chipping time, effective cutting speed, impact ratio, and surface generating area, which are used for evaluating the previously settled engagement conditions. Finally, the calculated values are plotted and visualized with a dedicated tool implemented in Matlab (Figure 7).

3.1.4. Calculation of the Boundary Curves. The typical chip form for ball-end milling, for the positive cross-axis case $\mathrm{C}+$, is depicted in Figure 8. This model was obtained by using a CSG model (constructive solid geometry) in the commercial CAD software Siemens NX. This approach is 


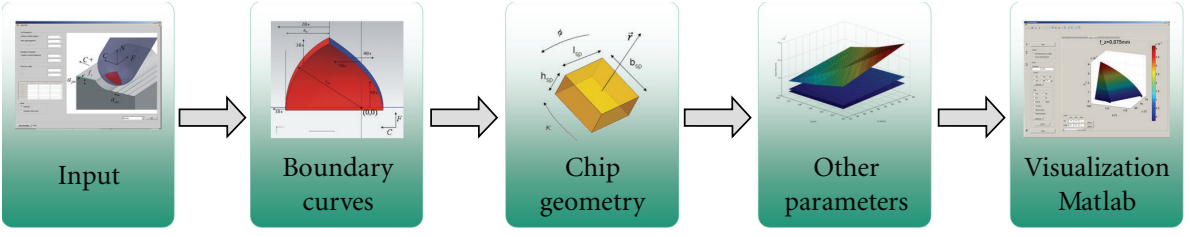

FIgURE 5: Simulation workflow.

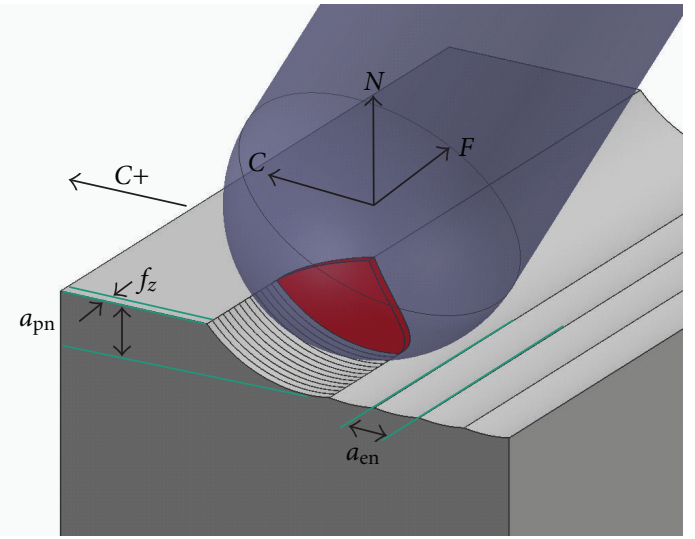

Figure 6: Contact conditions and reference system for ball-end milling.

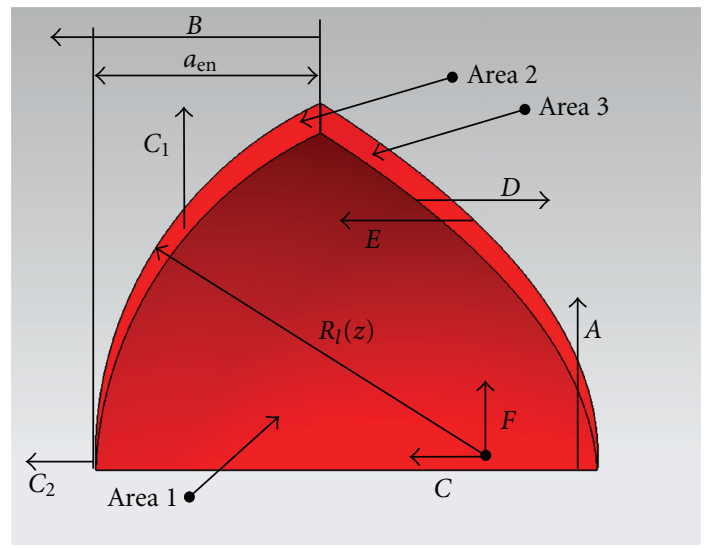

(a)

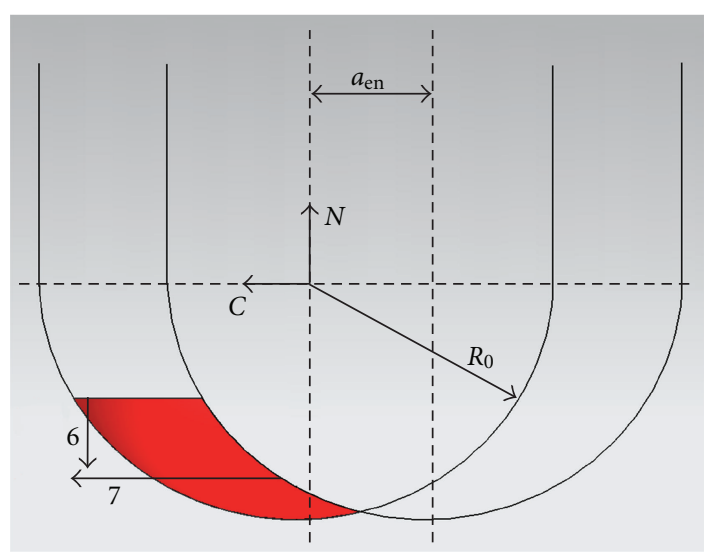

(b)

Figure 7: Definition of the boundary curves for the case C+. valid based on the assumption that the previous tool path is the intersection of a rectangular solid work piece and a cylinder along the $F$-axis, not considering the scallops in the feed direction. The scallops in the cross-feed direction are, however, considered. The chip form is, thus, the result of the consecutive subtraction of the resulting geometry and a sphere.

The tooth trajectory is considered circular, which is a very good approximation for finishing processes, since small feedrate values in comparison to the tool radius are normally used. It is important to note, furthermore, that the error resulting from this assumption increases when the contact area gets closer to the tool tip, since the local radius decreases and the actual path of the local cutting edge differs more from a circular path.

The indicated boundary curves for the positive cross-axis case are calculated as follows:

$$
\begin{aligned}
& A:=F \geq-\frac{f_{z}}{2}, \\
& B:=C \geq R_{l}-a_{\mathrm{en}}, \\
& C_{1,2}:= \begin{cases}\mathrm{C}_{1}:=F \geq \sqrt{R_{l}^{2}-C^{2}}-f_{z}, & \text { if } F \geq 0, \\
\mathrm{C}_{2}:=C \geq \sqrt{R_{l}^{2}-\left(F+f_{z}\right)^{2}}, & \text { else }(F \leq 0),\end{cases} \\
& D:=\left\{\begin{array}{l}
F \geq-\frac{f_{z}}{2}, \quad C \leq R_{l}-a_{e}, \\
C \leq-\frac{a_{\mathrm{en}}}{2}+\frac{F^{2}}{2 a_{\mathrm{en}}}+\frac{f_{z}}{a_{\mathrm{en}}} F+\frac{f_{z}^{2}}{2 a_{\mathrm{en}}},
\end{array}\right. \\
& E:=\left\{\begin{array}{l}
F \geq-\frac{f_{z}}{2}, \quad C \leq R_{l}-a_{\mathrm{en}}, \\
C \geq \frac{F^{2}}{2 a_{\mathrm{en}}}-\frac{a_{\mathrm{en}}}{2},
\end{array}\right. \\
& F:=C \geq \sqrt{R_{0}^{2}-N^{2}}-a_{\mathrm{en}}, \\
& G:=N \leq a_{\mathrm{pn}}-R_{0} .
\end{aligned}
$$

The results of the calculation of the boundary curves for the cases $\mathrm{C}+$ and $\mathrm{C}-$ are resumed in Table 3.

\subsubsection{Calculation of the Uncut Chip Geometry and Other} Parameters. The main parameters used for describing the chip geometry are the chip thickness $\left(h_{\mathrm{sp}}\right)$, chip width $\left(b_{\mathrm{sp}}\right)$, chip cross-sectional area $\left(A_{\mathrm{sp}}\right)$, and chip length $\left(l_{\mathrm{sp}}\right)$. The chip geometry parameters are described in Figure 8. The uncut chip is discretized in the $\Phi$ and $\kappa$ directions. The chip thickness is defined as the thickness of the material that is 
TABLE 3: Boundary curves for the case C+.

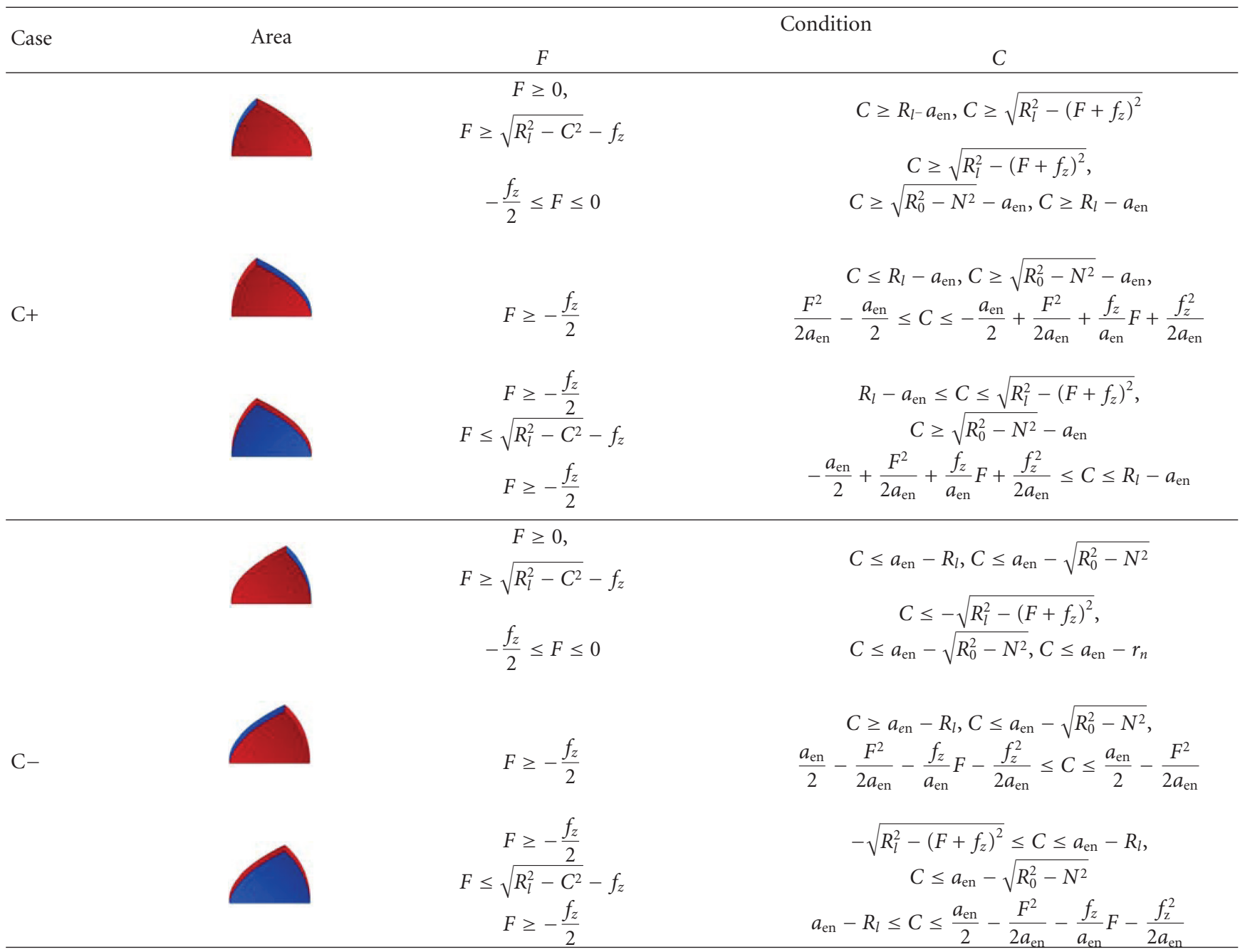

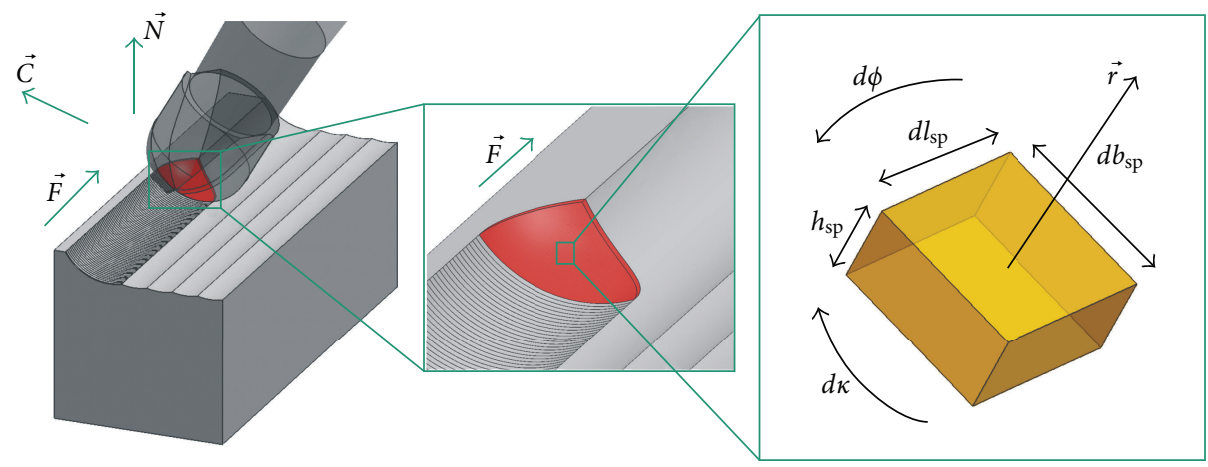

FIgURE 8: Uncut chip geometry.

removed in a certain cutting point $(\Phi, \kappa)$ of the tool in the normal direction of the cutting edge, that is, in the radial direction of the sphere. It can be approximated by the feed component in the radial direction, that is, the scalar product between the feed vector $\vec{F}=f_{z} \cdot \vec{f}$ and the sphere radial unity vector outward the surface $\vec{r}$ at a given cutting point [30]

$$
h_{\mathrm{sp}}(\Phi, \kappa)=f_{z} \cdot \vec{f} \cdot \vec{r}(\Phi, \kappa) .
$$




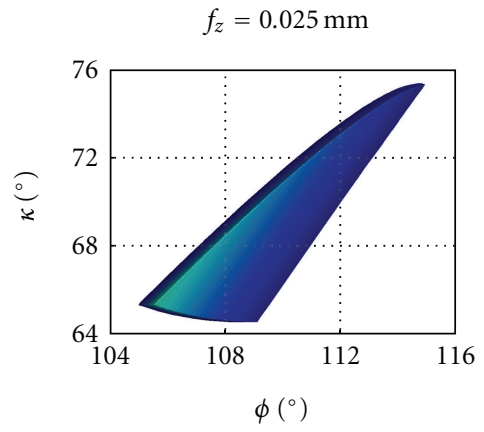

(a)

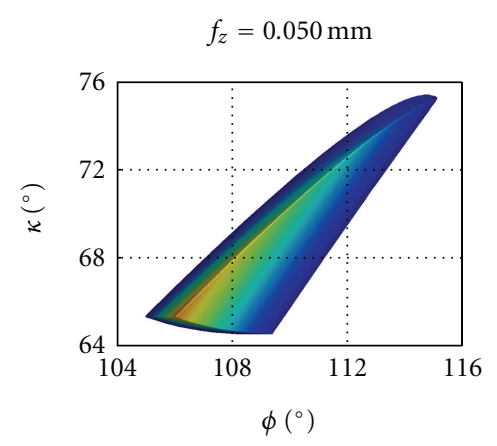

(b)

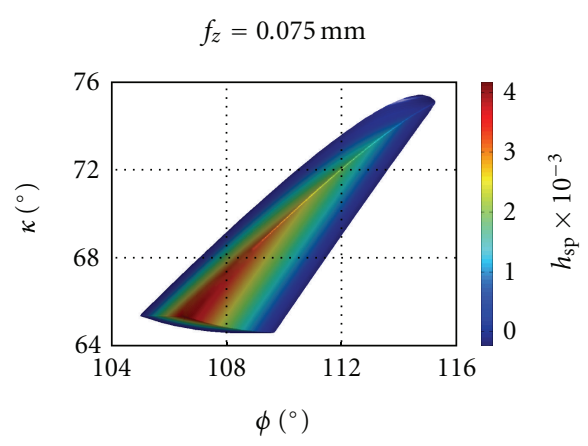

(c)

FIGURE 9: Influence of the feed-rate on the contact diagram.

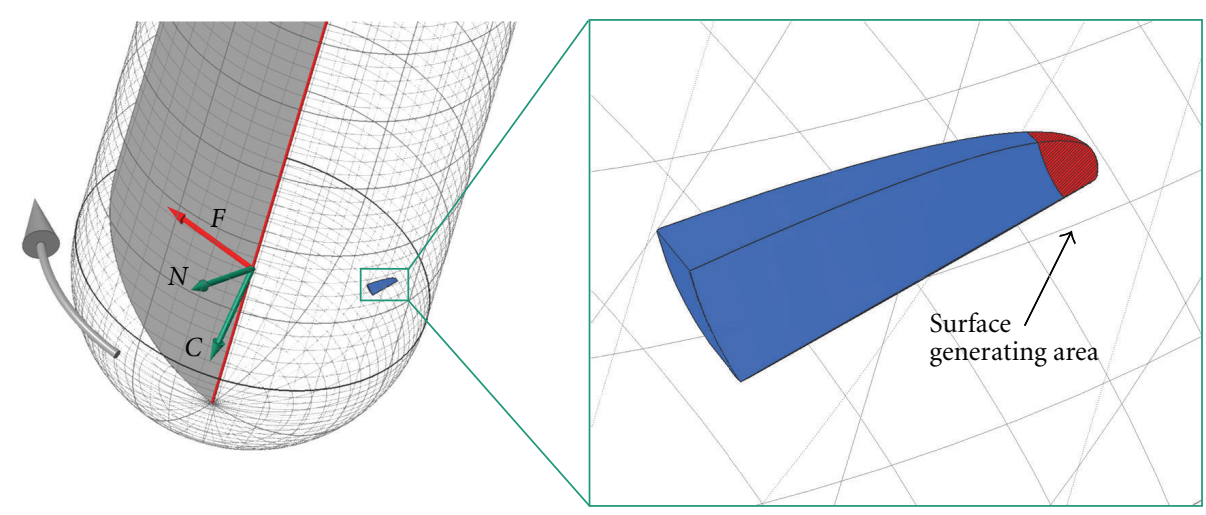

Figure 10: Chip position on ball-end mill for the simulation parameters.

The chip width is calculated along the $\kappa$ direction of the cutting tool and represents the actual contact width of the cutting edge and is given by

$$
\begin{aligned}
& d b_{\mathrm{sp}}(\kappa)=\frac{R_{0}}{\cos \left(\lambda_{l}(\kappa)\right)} d \kappa \\
& \Longrightarrow b_{\mathrm{sp}}(\Phi)=\int_{\kappa_{s}(\Phi)}^{\kappa_{e}(\Phi)} \frac{R_{0}}{\cos \left(\lambda_{l}(\kappa)\right)} d \kappa,
\end{aligned}
$$

where $\kappa_{s}$ and $\kappa_{e}$ are, respectively, the starting and ending axial immersion angle $\kappa$ for a given rotation angle $\Phi$.

The chip cross-sectional represents the contact area on each cutting edge for each rotation angle and for each and can be calculated as follows:

$$
\begin{aligned}
& d A_{\mathrm{sp}}(\Phi, \kappa)=h_{\mathrm{sp}}(\Phi, \kappa) \cdot d b_{\mathrm{sp}}(\Phi) \\
& \Longrightarrow A_{\mathrm{sp}}(\Phi)=\int_{\mathcal{K}_{\mathrm{s}}(\Phi)}^{\kappa_{e}(\Phi)} h_{\mathrm{sp}}(\Phi, \kappa) \cdot \frac{R_{0}}{\cos \left(\lambda_{l}(\kappa)\right)} d \kappa .
\end{aligned}
$$

The chip length is defined as the contact length for a constant axial tool immersion, that is, the engagement length of each tool slice

$$
d l_{s p}(\kappa)=R_{l}(\kappa) \cdot d \Phi \Longrightarrow l_{\mathrm{sp}}(\kappa)=\int_{\Phi_{s}(\kappa)}^{\Phi_{e}(\kappa)} R_{l}(\kappa) d \Phi
$$

where the chip volume is the volume removed by one flute in one tool revolution

$$
\begin{aligned}
& d V_{\mathrm{sp}}(\Phi, \kappa)=h_{\mathrm{sp}}(\Phi, \kappa) \cdot d b_{\mathrm{sp}}(\kappa) \cdot d l_{s p} \\
& \Longrightarrow V_{\mathrm{sp}}=\int_{\mathcal{K}_{\mathrm{sg}}}^{\kappa_{\mathrm{eg}}} \int_{\Phi_{\mathrm{sg}}}^{\Phi_{\mathrm{eg}}} h_{\mathrm{sp}}(\Phi, \kappa) \cdot \frac{R_{0}}{\cos \left(\lambda_{l}(\kappa)\right)} R_{l}(\kappa) d \Phi d \kappa,
\end{aligned}
$$

where $\kappa_{\mathrm{sg}}, \kappa_{\mathrm{eg}}$ are, respectively, the global starting and ending axial immersion angle and $\Phi_{\mathrm{sg}}, \Phi_{\mathrm{eg}}$ are the global starting and ending rotation angle. For the points outside the boundary conditions, $h_{\mathrm{sp}}(\Phi, \kappa)=0$.

3.2. Simulation Results. Table 4 resumes the input data for the simulation: the cutting speed varies along the tool axis, due to the variation of the local tool radius $R_{l}$. The closer to the tool tip the smaller the cutting speed and vice versa. The effective cutting speed was calculated on the surface generating area of the chip, which is the area where the actual cut generates a final surface which is not recut in the following tool engagement.

The chip position on the tool and the FCN coordinate system are shown in Figure 10. The position and orientation of the chip varies according to the tool orientation and cutting parameters. It should be noticed that for the simulation parameters, the surface generating area is on the top part of 


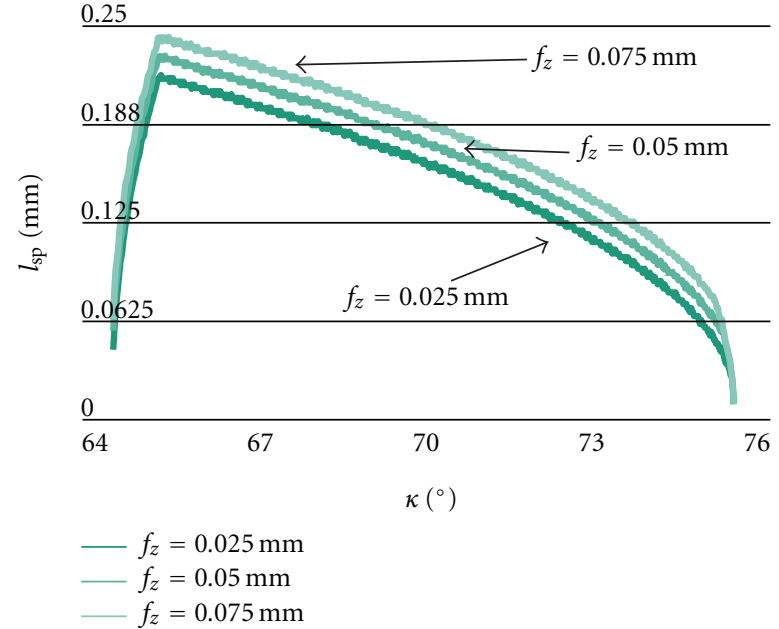

(a)

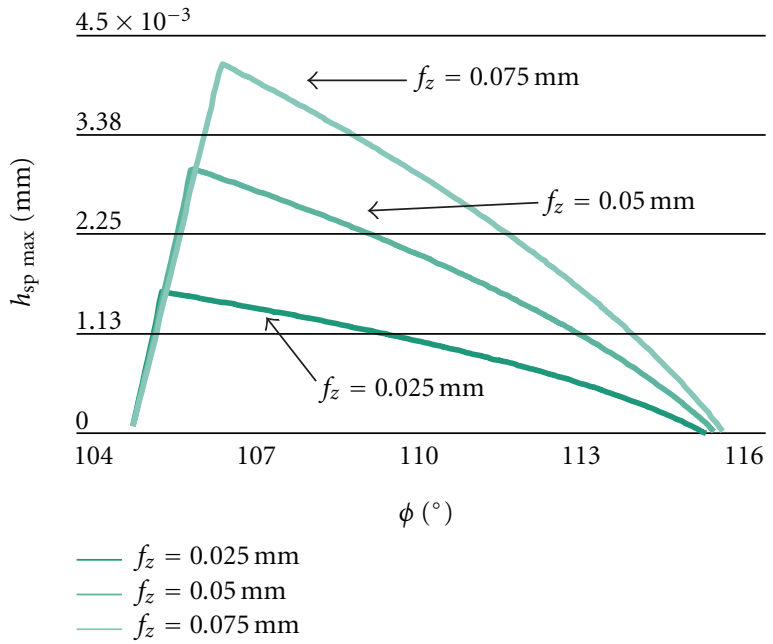

(c)

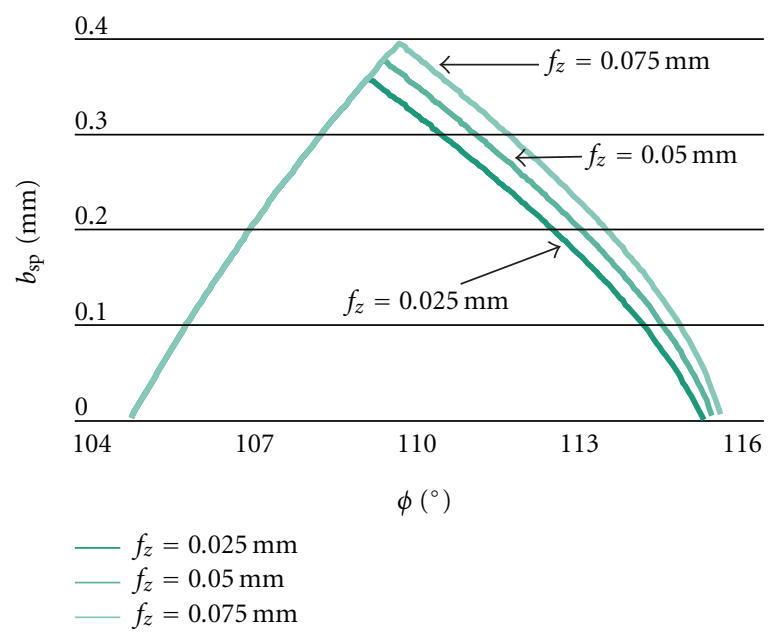

(b)

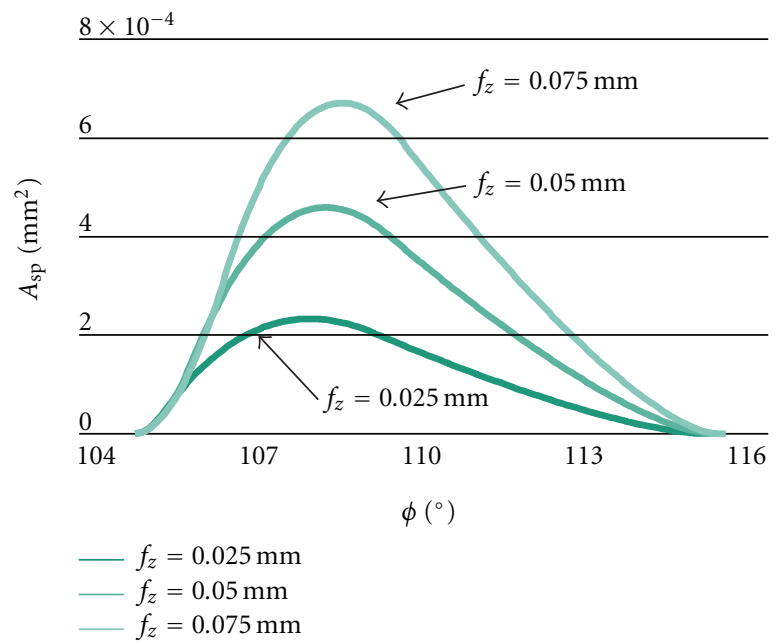

(d)

FIGURE 11: Influence of the feed-rate on the chip geometry.

the chip. This means that the end surface was generated by using the highest cutting speed of the entire removed volume.

Figure 9 shows the contact diagram for a feed variation. This diagram can be used for assessing the engagement condition and choose optimized parameters. It was introduced by Urban [31], however, without the colour information. The abscissa is the rotation angle $\Phi$ and the ordinate the axial immersion angle $\kappa$. The colours represent the chip thickness.

The cutting speed varies continuously along the ordinate, with a variation of $\kappa$. This means that the bottom part of the chip in this diagram is machined at a lower cutting speed than the upper part. The tool rotates in the positive direction of $\Phi$, which means that the left part of the chip in the diagram is removed earlier than the right part. The feed variation does not affect the contact region substantially, implying just in a light increase of the chip in the $\Phi$ direction what can also be observed in the Figures 11(a) and 11(b).

Nevertheless, the feed-rate has a high impact on the chip thickness and consequently on the chip cross-section area, which are shown, respectively, in Figures 11(c) and 11(d). These two parameters are very important for the prediction of the process forces and of the load collective on the cutting edge.

Higher forces are expected for higher feed-rate values. This effect can, however, be compensated by changing the tool orientation. A more longitudinal chip (see contact diagram) would result in a smaller chip cross-sectional area and consequently smaller processes forces. This would theoretically decrease the tool wear and, thus, increase the tool life.

Nevertheless, a more longitudinal chip also results in a higher chip length, which is directly related to the tool wear, since an increase of the contact length between the cutting edge and the workpiece also increases the abrasion and adhesion effects. A good balance between these two effects is a diagonal chip geometry, as used in this paper, which reduces the chip cross-sectional area and simultaneously keeps the chipping length in a moderate range. 

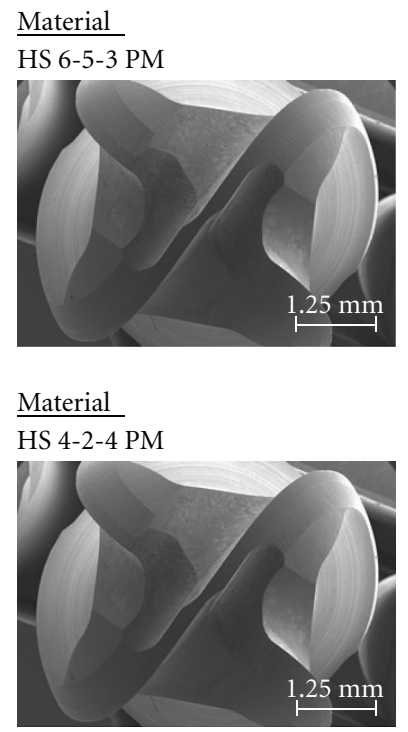

$v_{c, \mathrm{eff}}$

$225 \mathrm{~m} / \mathrm{min}$

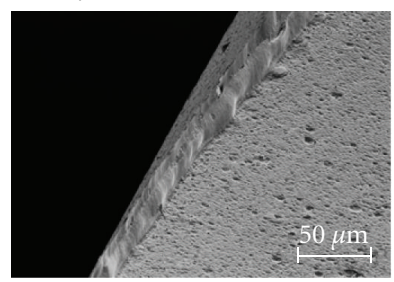

$v_{c, \text { eff }}$

$225 \mathrm{~m} / \mathrm{min}$

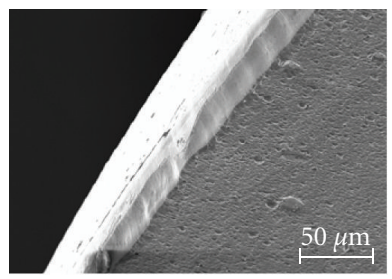

$\nu_{c, \mathrm{eff}}$

$300 \mathrm{~m} / \mathrm{min}$

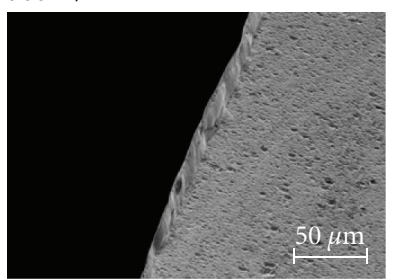

$v_{c, \text { eff }}$

$300 \mathrm{~m} / \mathrm{min}$

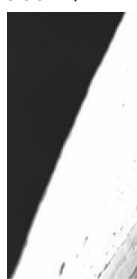

$v_{c, \mathrm{eff}}$

$400 \mathrm{~m} / \mathrm{min}$

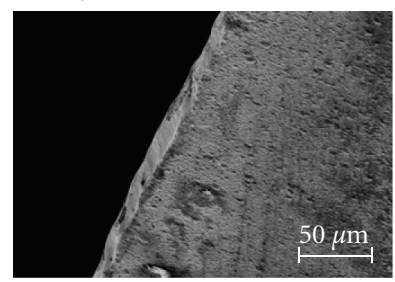

$v_{c, \mathrm{eff}}$

$400 \mathrm{~m} / \mathrm{min}$

Figure 12: Tool wear qualification.

TABLe 4: Simulation input data.

\begin{tabular}{lc}
\hline Cutting tool & 6 \\
Tool diameter $D_{0}(\mathrm{~mm})$ & 4 \\
Number of Flutes $n$ & 30 \\
Helix angle $\lambda\left(^{\circ}\right)$ & 21 \\
Local helix angle $\lambda_{l}\left(^{\circ}\right)$ & \\
\hline Cutting parameters & 225,300 , and 400 \\
Effective cutting speed $v_{c, \text { eff }}(\mathrm{m} / \mathrm{min})$ & 233,311 , and 414 \\
Cutting speed at shaft $v_{c}(\mathrm{~m} / \mathrm{min})$ & $0.025,0.05$, and 0.075 \\
Feed per tooth $f_{z}(\mathrm{~mm})$ & 0.05 \\
Row width $a_{\mathrm{en}}(\mathrm{mm})$ & 75 \\
Cutting depth $a_{\mathrm{pn}}(\mathrm{mm})$ & $\mathrm{C}+$ \\
Tilt angle $\beta_{\mathrm{fn}}\left({ }^{\circ}\right)$ & \\
Workpiece position & 0.05 \\
\hline Simulation parameters & 0.02 \\
Discretization along the rotation angle $d \Phi\left(^{\circ}\right)$ & \\
Discretization along the axial & \\
immersion angle $d \kappa\left(^{\circ}\right)$ & \\
\hline
\end{tabular}

\section{Experimental Results and Discussion}

4.1. Qualification and Quantification of the Milling Tool Wear. Figure 12 exposes the qualified tool flank wear land (VB) morphology after reaching an abort criterion of $75 \mu \mathrm{m}$ in terms of varying the work piece material and the effective cutting speed $v_{c \text {,eff. }}$

While increasing $v_{c \text {, ff }}$ in machining both materials the characteristic abrasion of the tool flank developed progressively homogenous without any hinds of cutting-edge fracture, cracking, and shell-shaped spalling of the TiAlNcoating on the flank of the rake face. While increasing $v_{c, \text { eff }}$ in machining of HS 4-2-4 PM a noticeable increase in adhesion related tool flank wear was observed.
In the case of the high-speed steel HS 6-5-3 PM (64 HRC) the tool flank wear land $\mathrm{VB}$ evolved nearly linear with a progressing cutting length $L_{c}$ at each parameter setting; see Figure 13. In the beginning of machining, a characteristic initial abrasive wear evolved until reaching a $L_{c}$ of nearly $25 \mathrm{~m}$, where the wear development curve slightly flattened until $L_{c, \max }$ was reached.

Conversely to Elbestawi et al. [12], the introduced, however not proved, hypothesis of Salomon [13] is confirmed, stating that for an increase of $v_{c \text {,eff }}$ from $225 \mathrm{~m} / \mathrm{min}$ up to $300 \mathrm{~m} / \mathrm{min}$ the maximum cutting length $L_{c \text {, max }}$ is improved by $33 \%$. After performing of milling tests at $v_{c, \text { eff }}=$ $400 \mathrm{~m} / \mathrm{min}$ a further tool life improvement in respect to a $v_{c, \text { eff }}$ of $300 \mathrm{~m} / \mathrm{min}$ was detected.

Although the cold working steel HS 4-2-4 PM (66 HRC) is slightly harder than HS 6-5-3 PM (64 HRC), a $L_{c \text {, max }}$ better than $200 \mathrm{~m}$ was proofed.

After reaching $60 \mathrm{~m}$ in cutting length, the wear evolution curve significantly flattened for each cutting speed setting and rose linearly until $L_{c \text {, max }}$. The abort criterion of $75 \mu \mathrm{m}$ in VB was first detected after $220 \mathrm{~m}$ of cutting length at an $v_{c, \text { eff }}$ of $225 \mathrm{~m} / \mathrm{min}$. $L_{c}$ increased nearly linear with increasing $v_{c, \text { eff. }}$

Additionally, in Figure 14, for clarifying the influence of feed per tooth $f_{z}$ regarding the wear evolution of the milling tool on a random basis, $f_{z}$ was varied in terms of $0.025,0.05$, and $0.075 \mathrm{~mm} /$ tooth at a $v_{c, \text { eff }}$ of $300 \mathrm{~m} / \mathrm{min}$ for both work piece materials.

It was found out that depending on the material characteristics of HS 4-2-4 PM in a narrow cutting parameter range a decreasing feedrate negatively influenced $L_{c, \max }$. Increasing $f_{z}$ from $0.05 \mathrm{~mm} /$ tooth $\left(L_{c}=240 \mathrm{~m}\right)$ up to $0.075 \mathrm{~mm} /$ tooth accompanied with an significant improvement in cutting length up to $320 \mathrm{~m}$. Hence, on the other hand, increasing $f_{z}$ increases the cusp to valley which accompanies with an increased surface roughness. At first appearance, this 


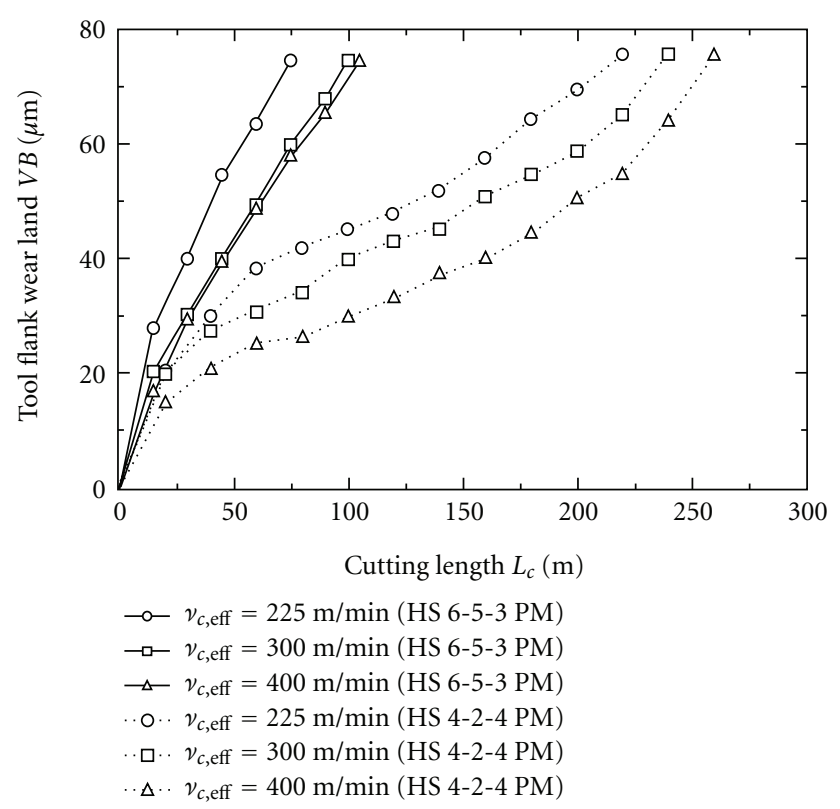

FIGURE 13: Influence of varied work piece material and varied effective cutting speed on the tool flank wear land.

result is legitimate, because during machining with $f_{z}=$ $0.025 \mathrm{~mm} /$ tooth in regard of $f_{z}=0.075 \mathrm{~mm} /$ tooth each flute of the milling tool is exposed with a tripled impact peak with the work piece surface per considered cutting length. Interestingly, in case of the HS 6-5-3 PM, in a narrow parameter range the influence of the impact peak per cutting length is nearly negligible. For further investigating the influence of $f_{z}$ to the tool flank wear land VB, the friction inclination length $L_{\text {In }}$ of the tool, respectively, to the work piece surface was presented in Figure 15. Interestingly, considering only $\mathrm{VB}$ as an function of $L_{\mathrm{RF}}$, decreasing $f_{z}$ to $0.025 \mathrm{~mm}$ accompanies with a drastically increasing of tool life in comparison to $f_{z}=0.05$ and 0.075 . This observation indicates that the impact peak alone is by far not the determining factor for tool wear.

Contrary to comparable investigations, it can be supposed that the increased inclination length in terms of lower $f_{z}$ and the microscopic structural integrity especially the thermal conductivity of the work piece material have a great influence to the microscopic flow behaviour and hence a significant effect on the tool life and wear characteristic of the milling tool. Considering the investigated materials, the thermal conductivity of HS 6-5-3 PM $(24 \mathrm{~W} / \mathrm{mk})$ is significantly higher compared to HS 4-2-4 PM (19,6 W/mK). So, it can be suggested that the thermal conductivity $k$ has an important influence on the chipping mechanisms in highspeed dry-hard milling. With increased thermal conductivity the thermal transfer resistance decreases, and the thermal energy of the chipping process can easily penetrate into the work piece surface instead through the chip. Hence, due to an advanced thermal load in the subsurface area around the contact point between tool and work piece the plasticisation of the work piece material and the softening of the chip improves. In this case, it is expected, because of the relatively low thermal conductivity of HS 4-2-4 PM, that the amount

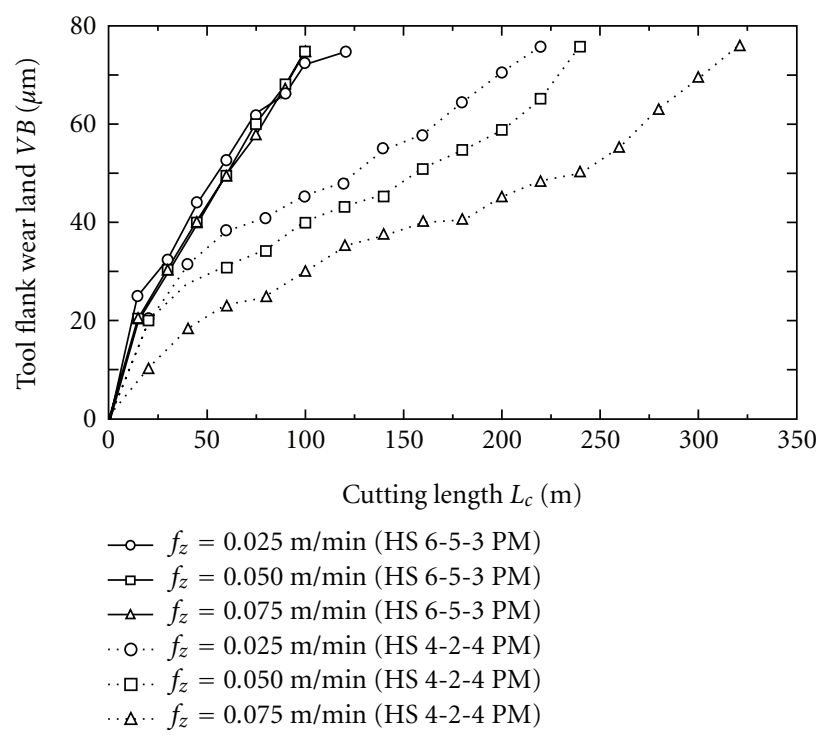

FIGURE 14: Influence of varied work piece material and fead per tooth on the tool flank wear land at $v_{c, \text { eff }}=300 \mathrm{~m} / \mathrm{min}$.

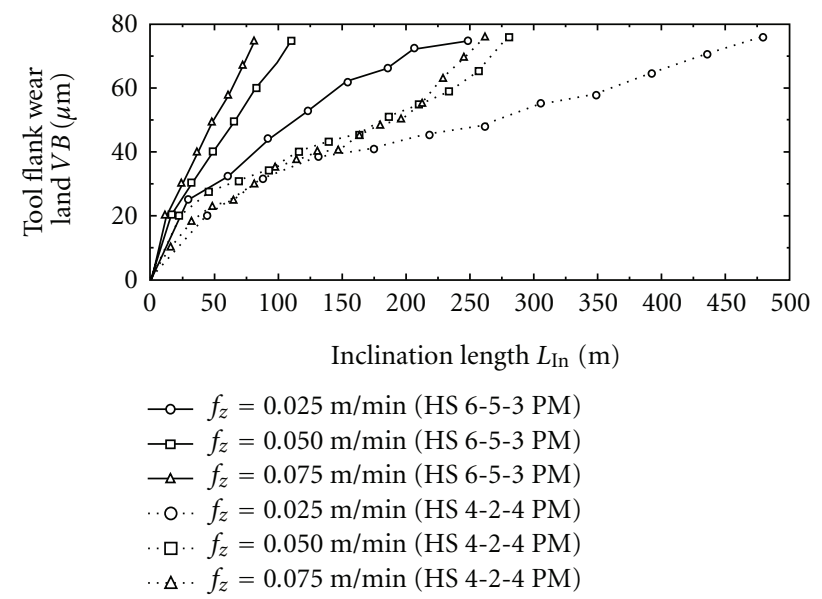

Figure 15: Influence of varied work piece material and the inclination cutting length on the tool flank wear land.

of thermal energy generated in the chipping process, which dissipated through the chips, was significantly higher than in HS 6-5-3 PM. On the other hand, in HS 4-2-4 PM the size of carbides is significantly smaller and the distribution of the carbides is more homogenous compared to HS 6-53 PM. Hence, friction resistance in the contact zone between work piece and milling tool will be significantly lower in HS 4-2-4 PM. Hence, the local thermal impact to the subsurface area of the work piece will be noticeable reduced and the machinability of HS 4-2-4 PM and the cutting performance of the solid carbide ball-end mills drastically enhanced due both the thermal conductivity as well as the microstructural integrity of the material.

4.2. Quantification of Process Forces. Increasing of the effective cutting speed $v_{c \text {,eff }}$ in machining HS 6-5-3 PM generated 


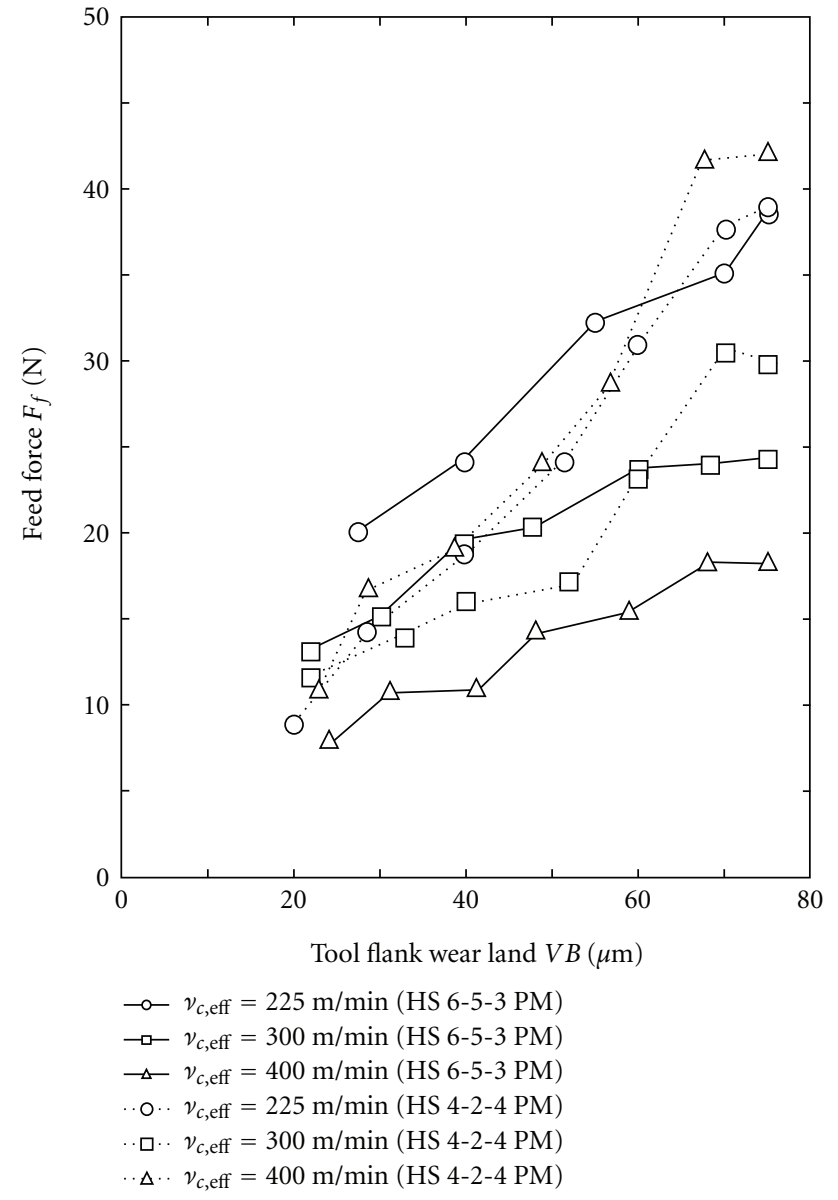

FIGURE 16: Influence of varied work piece material and progressing tool flank wear land on the resulting feed force.

elevated process temperatures, hence the plasticisation of the work piece material enhanced and process force, especially the feed force $F_{f}$ (Figure 16), significantly decreased.

$F_{f}$ increased proportionally with progressive tool flank wear land VB. With advanced $v_{c \text {,eff }}$ the curve of the $F_{f}$ with progressing VB significantly flattened. Machining with $v_{c, \text { eff }}=400 \mathrm{~m} / \mathrm{min}$ considering $225 \mathrm{~m} / \mathrm{min}$, resulted in reduction of $F_{f}$ by nearly $50 \%$. In machining HS 4-2-4 PM, the $F_{f}$ curve increased more sharply with advanced cutting speeds. Interestingly, while machining with a fresh tool at VB $\sim 20 \mu \mathrm{m}$, for each $v_{c, \text { eff }} F_{f}$ evolved from nearly a range of 9 to $14 \mathrm{~N}$. After reaching the abort criterion of $75 \mu \mathrm{m}$ in terms of $\mathrm{VB}$, a maximum feed force $F_{f, \max }$ of $39 \mathrm{~N}$ for $225 \mathrm{~m} / \mathrm{min}$, $30 \mathrm{~N}$ for $300 \mathrm{~m} / \mathrm{min}$, and $43 \mathrm{~N}$ for $400 \mathrm{~m} / \mathrm{min}$ in effective cutting speed were quantified.

After performing of milling tests on both work piece materials with fresh tools at $v_{c, \text { eff }}$ of $400 \mathrm{~m} / \mathrm{min}$ and $f_{z}$ of $0.05 \mathrm{~mm}$ a roughness of $R_{a}<0.12 \mu \mathrm{m}$ was measured.

\section{Conclusion}

In order to characterise the cutting force related wear progression and cutting performance of solid carbide ball-end mills in high-speed dry-hard milling of hardened powder metallurgical steels, the tool wear flank land, the cutting length, and the process forces were investigated.

(1) While increasing the effective cutting speed in machining of two powder metallurgical produced steels, HS 6-5-3 PM (64 HRC) and a HS 4-2-4 PM (66 HRC), a characteristic abrasion of the used solid carbide ball-end mills developed progressively homogenous.

(2) An iterative increase in effective cutting speed resulted in a significantly enhanced tool life.

(3) Depending on the material characteristics of the investigated work piece materials, in a narrow cutting parameter range an increased federate was accompanied by an enhanced tool life.

(4) Increasing of the effective cutting speed $v_{c \text {,eff }}$ in machining HS 6-5-3 PM resulted in a significantly decreased feed force and enhanced tool life.

(5) In machining HS 4-2-4 PM the feed force increased more sharply with advanced cutting speeds while tool life was tripled in regard to HS 6-5-3 PM.

(6) It was supposed that with decreased thermal conductivity of the considered work piece material the thermal transfer resistance increases, and hence, the local thermal impact to the subsurface area of the work piece will be noticeable reduced as well as the cutting performance of the solid carbide ball-end mills drastically enhanced.

\section{References}

[1] I. Jung, "Moderne Hochleistungsstähle für den Formenund Werkzeugbau, Tagungsunterlagen," in Proceedings of the Seminar für Werkzeugtechnik, 2002.

[2] D. Biermann, A. Baschin, E. Krebs, and J. Schlenker, "Manufacturing of dies from hardened tool steels by 3-axis micromilling," Production Engineering, Research and Development, vol. 5, no. 2, pp. 209-217, 2011.

[3] B. Denkena, D. Boehnke, and R. Meyer, "Reduction of wear induced surface zone effects during hard turning by means of new tool geometries," Production Engineering, Research and Development, vol. 2, no. 2, pp. 123-132, 2008.

[4] H. K. Tonshoff, C. Arendt, and R. Ben Amor, "Cutting of hardened steel," Annals of the CIRP, vol. 49, no. 2, pp. 547$566,2000$.

[5] F. Klocke, S. Knodt, S. Altmüller, and A. Bilsing, "Fräsverfahren stellen hohe ansprüche an werkzeug und maschine," Werkstattstechnik Wt, vol. 89, no. 10, pp. 451-455, 1999.

[6] F. Klocke, V. Zinkann, and K. Gerschwiler, "Hochleistungswerkstoffe erfordern angepasste Bearbeitungstechnologien," VDI-Z, vol. 139, no. 6, pp. 18-24, 1997.

[7] R. Piotrowiak, V. Schüler, I. Schruff, and C. Spiegelhauer, "Sprühkompaktierte Hochleistungs-Werkzeugstähle," HTM Zeitschrift für Werkstoffe, Wärmebehandlung und Fertigung, vol. 59, no. 6, pp. 423-431, 2004.

[8] A. Schulz, E. Matthaei-Schulz, S. Spangel, R. Tinscher, H. Vetters, and P. Mayr, "Das primärgefüge sprühkompaktierter 
stähle," HTM Zeitschrift für Werkstoffe, Wärmebehandlung und Fertigung, vol. 56, no. 2, pp. 104-109, 2001.

[9] A. Schulz, V. Uhlenwinkel, C. Escher et al., "Sprühkompaktierte hochlegierte werkzeugstähle-herstellung und eigenschaften," HTM Zeitschrift für Werkstoffe, Wärmebehandlung und Fertigung, vol. 60, no. 2, pp. 87-95, 2005.

[10] Y. Matsumoto, M. M. Barash, and C. R. Liu, "Cutting mechanisms during machining of hardened steels," Materials Science and Technology, vol. 3, no. 4, pp. 299-305, 1987.

[11] J. Köhler, Berechnung der zerspankräfte bei variierenden spanungsquerschnittsformen, Doctoral thesis, Hannover, Germany, 2010.

[12] M. A. Elbestawi, L. Chen, C. E. Becze, and T. I. El-Wardany, "High-speed milling of dies and molds in their hardened state," Annals of the CIRP, vol. 46, no. 1, pp. 57-62, 1997.

[13] C. Salomon, "Verfahren zur bearbeitung von metallen oder bei einer bearbeitung durch schneidende werkzeuge sich ähnlich verhaltende werkstoffe," Deutsches Patent Nr. 523594, 931, 4, 1931.

[14] F. Klocke and W. König, Fertigungsverfahren Drehen, Fräsen, Bohren, vol. 8, Springer, Berlin, Germany, 2008.

[15] P. Koshy, R. C. Dewes, and D. K. Aspinwall, "High speed end milling of hardened AISI D2 tool steel ( 58 HRC)," Journal of Materials Processing Technology, vol. 127, no. 2, pp. 266-273, 2002.

[16] M. Okada, A. Hosokawa, R. Tanaka, and T. Ueda, "Cutting performance of PVD-coated carbide and CBN tools in hardmilling," International Journal of Machine Tools and Manufacture, vol. 51, no. 2, pp. 127-132, 2011.

[17] F. Klocke and V. Zinkann, "Hochgeschwindigkeitsbearbeitung ändert die Spanbildung," VDI-Z, vol. 141, no. 3-4, pp. 30-34, 1999.

[18] E. El-Magd and C. Treppmann, "Mechanical behaviour of materials at high strain rates," Scientific Fundamentals of HSC, pp. 113-136, 2001.

[19] S. Knodt, Hartfräsen pulvermetallurgisch erzeugter ledeburitischer Werkzeugstähle, Doctoral thesis, Aachen, Germany, 2004.

[20] M. Soković, J. Kopać, L. A. Dobrzański, and M. Adamiak, "Wear of PVD-coated solid carbide end mills in dry highspeed cutting," Journal of Materials Processing Technology, vol. 157-158, pp. 422-426, 2004.

[21] Y. S. Liao and H. M. Lin, "Mechanism of minimum quantity lubrication in high-speed milling of hardened steel," International Journal of Machine Tools and Manufacture, vol. 47, no. 11, pp. 1660-1666, 2007.

[22] R. Ben Amor, Thermomechanische Wirkmechanismen und Spanbildung bei der Hochgeschwindigkeitszerspanung, Doctoral thesis, Hannover, Germany, 2003.

[23] M. Elbestawi, M. Dumitrescu, T. I. El-Wardany, and J. Böhner, "Effect of carbide tool grades and cutting edge geometry on tool life during high speed machining of hardened tool steel," in Proceedings of the 2nd International Conference on High Speed Machining, pp. 37-46, 1999.

[24] Y. Altintaș and P. Lee, "Mechanics and dynamics of ball end milling," Journal of Manufacturing Science and Engineering, Transactions of the ASME, vol. 120, no. 4, pp. 684-692, 1998.

[25] Y. Altintas, Manufacturing Automation, Metal Cutting Mechanics, Machine Tool Vibrations, and CNC Design, Cambridge University Press, New York, NY, USA, 2000.

[26] A. Zabel, Prozesssimulation in der zerspanung-modellierung von dreh und fräsprozessen, Habilitation thesis, Dortmund, Germany, 2010.

[27] C. A. van Luttervelt, T. H. C. Childs, I. S. Jawahir et al., "Present situation and future trends in modelling of machining operations progress report of the CIRP working group "modelling of machining operations," CIRP AnnalsManufacturing Technology, vol. 47, no. 2, pp. 587-624, 1998.

[28] I. Lazoglu and S. Y. Liang, "Modeling of ball-end milling forces with cutter axis inclination," Journal of Manufacturing Science and Engineering, vol. 122, no. 1, pp. 3-11, 2000.

[29] R. Zhu, S. G. Kapoor, and R. E. DeVor, "Mechanistic modeling of the ball end milling process for multi-axis machining of free-form surfaces," Journal of Manufacturing Science and Engineering, vol. 123, no. 3, pp. 369-379, 2001.

[30] E. Ozturk and E. Budak, "Modeling of 5-axis milling processes," Machining Science and Technology, vol. 11, no. 3, pp. 287-311, 2007.

[31] B. Urban, Kinematische und mechanische wirkungen des kugelkopffräsens, Doctoral thesis, Hannover, Germany, 2009. 

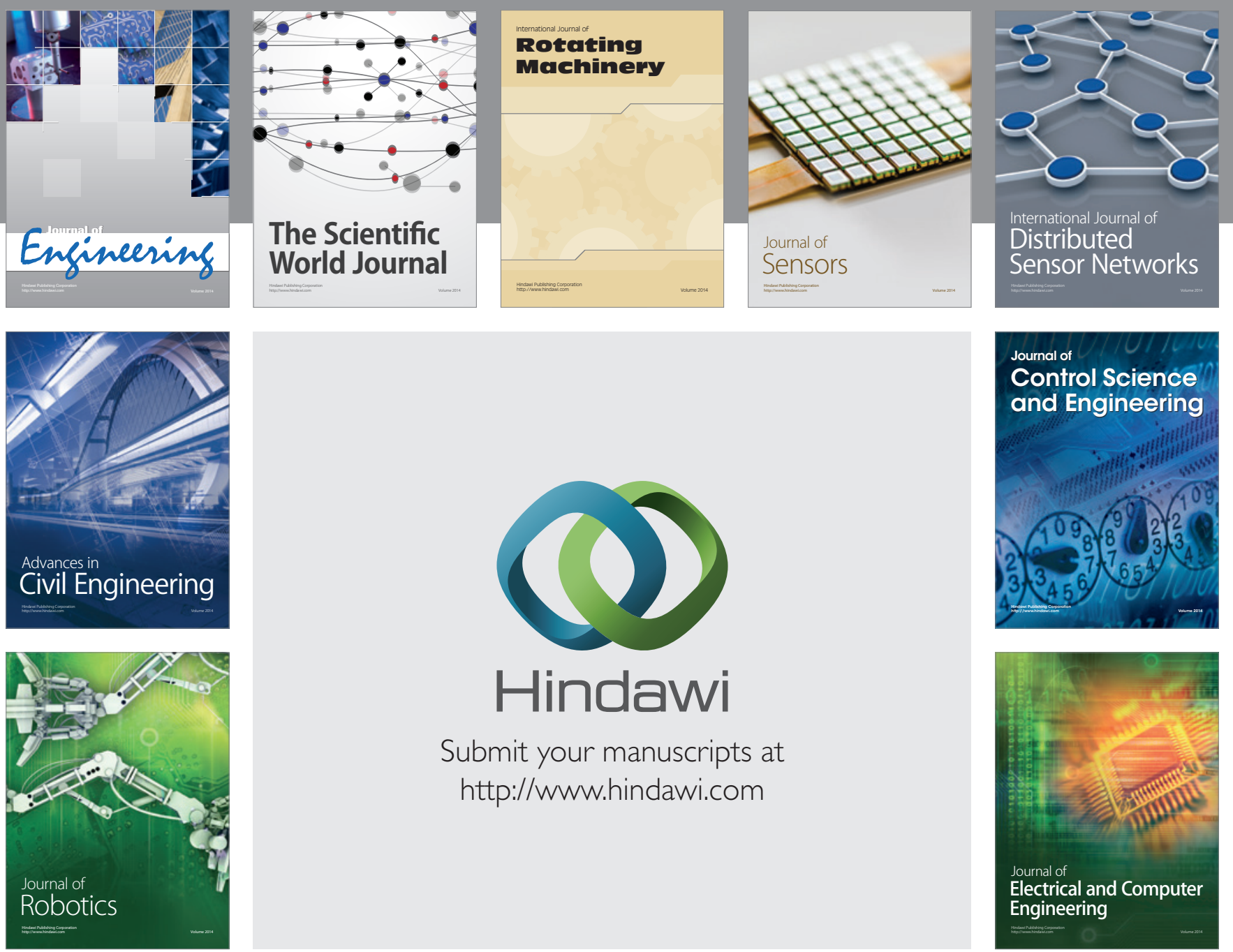

Submit your manuscripts at

http://www.hindawi.com
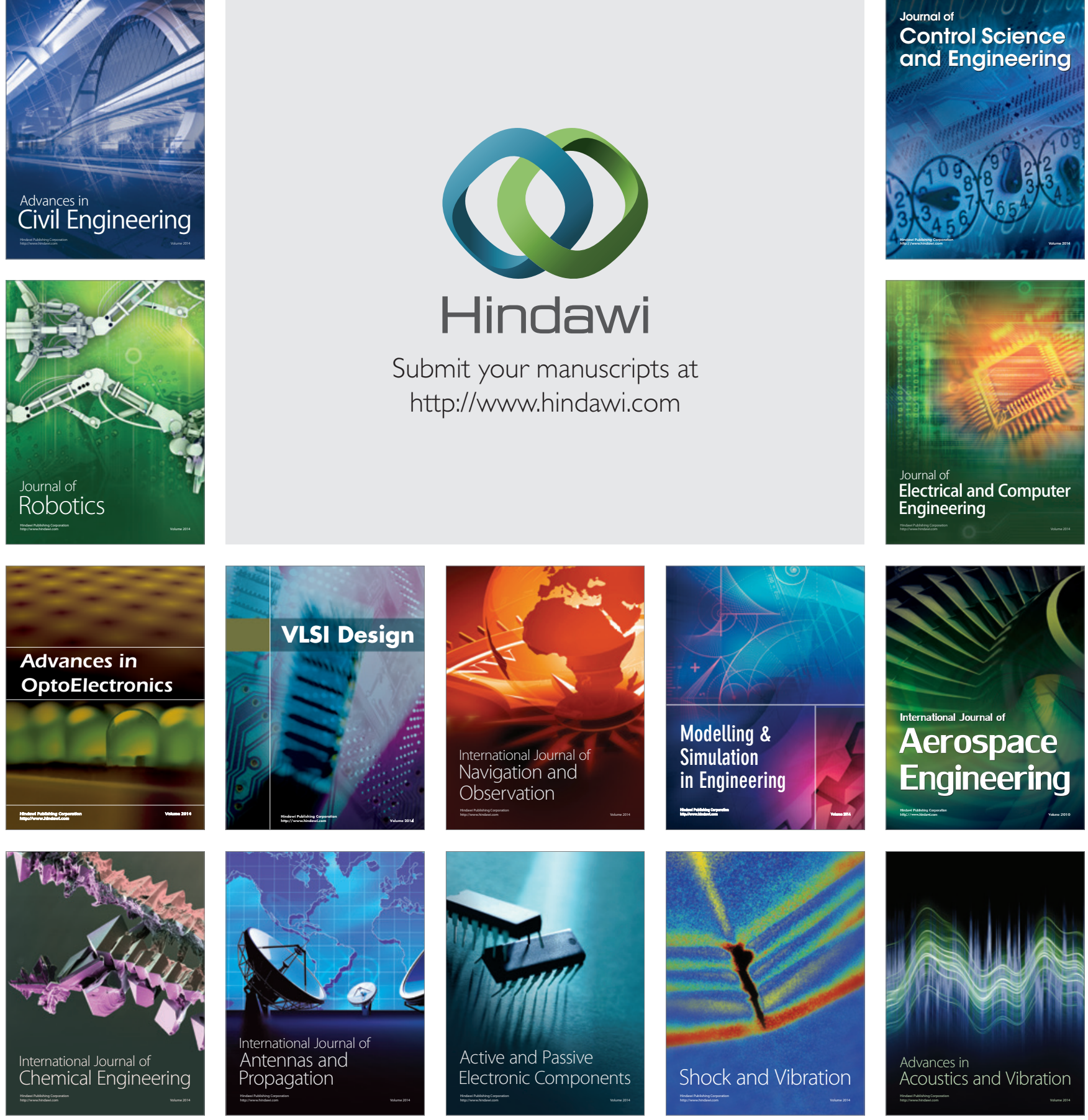